Alcaide Ramírez, Aurora.

Profesora Contratada Doctora, Universidad de Murcia, Departamento de Bellas Artes,

Grupo de Investigación Arte y Políticas de Identidad.

\title{
Paisajes enantrópicos. Un proyecto que reflexiona sobre las relaciones Hombre-Naturaleza en el espacio (peri)urbano abandonado.
}

\section{Enanthropic Landscapes. A project that reflects on the relations Man-Nature in the abandoned (peri)urban space.}

TIPO DE TRABAJO:

Comunicación.

PALABRAS CLAVE:

Antropización del paisaje; enantropía; periferia urbana; arte y naturaleza, pintura expandida.

KEY WORDS:

Antropization of the Landscape; Enanthropy; Urban Periphery; Art and Nature; Expanded Painting.

RESUMEN.

Esta ponencia versa sobre el proyecto pictórico personal titulado Paisajes enantrópicos que reflexiona sobre las conexiones hombre-naturaleza en los territorios metropolitanos abandonados: lugares en los que la naturaleza se aprovecha de la ausencia humana para reapropiarse del espacio que originalmente fue suyo, devolviéndole su aparente caos primigenio; entropía que el hombre anuló al imponer su dominio y control (antropización) y, en definitiva, al sustituir el paisaje natural por el artificial.

\section{ABSTRACT.}

This paper is about the personal pictorial project titled Enanthropic Landscapes that reflects on the man-nature connections in the abandoned metropolitan territories: places where nature takes advantage of human absence to reappropriate the space that was originally its, giving back its apparent chaos primal; entropy that the man annulled when imposing his dominion and control (antropización) and, in short, replacing the natural landscape with the artificial one.

\section{CONTENIDO.}

Introducción.

La evolución del ser humano se ha desarrollado en estrecha relación con su entorno. Si en un principio el impacto del hombre en la naturaleza era mínimo, el derivado exclusivamente de su uso como proveedora de alimentos y cobijo; con el transcurrir de los años la manipulación del medio natural se ha incrementado de manera exponencial, llegando en algunos casos incluso a peligrar la supervivencia de los seres que lo habitan, así como sus elementos constitutivos básicos. 
Como señala Francesco Careri, ${ }^{1}$ de una construcción simbólica del territorio en la época prehistórica, cuyo fin era principalmente dotar de significados a la naturaleza, se ha pasado a una construcción real de ésta: el hábitat natural se ha ido vaciando progresivamente de significados y llenando de objetos. Lo local, lo autóctono, la naturaleza salvaje y primigenia, ha sido sustituida en infinitud de zonas de la Tierra por extensas ciudades tecnificadas, con grandes avenidas, elevados rascacielos, modelos arquitectónicos y urbanísticos homogéneos, altas cotas de contaminación y exceso de rapidez e inmediatez, en donde lo natural pervive como mera anécdota: una hilera de árboles a lo largo de una calle, un escueto parque, una maceta... o peor aún, reducido a pura simulación, representación o fantasía mitificada: un jarrón con flores de plástico, papel de empapelar estampado con motivos vegetales, un póster de un paisaje paradisíaco... En palabras de Rosa Olivares: ${ }^{2}$

Nos hemos vuelto ciudadanos, vivimos en las ciudades, en las que un árbol, tal vez un parque, un jardín a veces, unos tiestos de vez en cuando, conforman la idea de naturaleza. Si el paisaje es una construcción cultural, la naturaleza es un recuerdo desvaído. Parte de una memoria colectiva que se aleja cada vez más rápido y de la que cada uno tiene una añoranza diferente. Nos hemos ido alejando de la naturaleza, pero la idea de lo que es, de la apariencia de la naturaleza, la hemos reconstruido, la hemos domesticado y la hemos convertido en elemento decorativo. Como todo lo perdido, la naturaleza se fija en nuestro inconsciente más profundo, y ese inconsciente hace que nos compremos una camisa de flores, un vestido que parece un jardín; hace que llenemos la casa con jarrones de flores, que guardemos flores secas entre las páginas de un libro...

Sin embargo, y a pesar de este panorama desolador, la actitud de la naturaleza no ha sido la de impasividad ante la hegemonía humana, sino que ha sabido buscar fisuras en su plan de ordenamiento urbano a través de las cuales filtrarse y desarrollar sigilosamente la recuperación de su hábitat; una reapropiación del territorio especialmente significativa en contextos y momentos históricos caracterizados por una economía en retroceso, como el actual. La era global presente se distingue por ciclos económicos que determinan y regulan los ritmos vitales de las ciudades, de ahí que en épocas de crisis -como la vivida en los últimos años en Occidente- afloren en las urbes y su periferia espacios abandonados, que tras adquirir el carácter de ruina, con el tiempo en numerosas ocasiones son vaciados, transformándose en descampados; no lugares -usando la terminología de Marc Augé ${ }^{3}$ - que la naturaleza reconquista aprovechando su situación de ser dominio de nadie (humano).

En opinión de Carlos Javier Rodríguez Sánchez -quien a su vez basa sus argumentaciones en Steve Harrison y Paul Dourish- "los espacios son transformados en lugares por los habitantes, a través de sus interpretaciones, sus interacciones sociales y su construcción a través de la experiencia". "Extrapolando esta afirmación al ámbito natural y partiendo de una perspectiva "naturocéntrica", se podría aseverar que el espacio muta a "lugar" no sólo en la medida en la que es utilizado socialmente por el ser humano, sino también en el momento en el que la naturaleza se despliega por sus confines y le otorga un sentido al habitarlo. Es entonces cuando el que era considerado un "no lugar" desde el punto de vista humano, se convierte en "lugar": en espacio de la actividad de la naturaleza. Pero también en un geosistema, ya que en estos espacios banales del interior de las ciudades o de su extrarradio, la huella del hombre, si bien desdibujada e imprecisa, está presente, aunque sea de forma latente. En ellos, a los que se ha optado por denominar -persiguiendo un juego de palabras- "paisajes enantrópicos", antropía y entropía se abrazan, a veces en perfecta simbiosis, otras de manera forzada. Como se apuntara en otro texto, ${ }^{5}$ estas zonas se caracterizan por ser:

(...) lugares abandonados por el hombre, en donde quedan restos de su presencia, pero en los que también se advierte la reapropiación ejercida por la naturaleza. Francesco Careri los define como "zonas (...) condenadas al olvido (...), territorios en los que se percibe el carácter transitorio de la materia, del tiempo y del espacio, y en donde la naturaleza recupera una nueva wilderness, un estado salvaje híbrido, ambiguo y antropizado, que escapa al control humano para poder ser reabsorbido por la naturaleza" (...). Estos lugares están conectados con la segunda definición de "entropía” recogida por la RAE: "Magnitud termodinámica que mide la parte no utilizable de la energía contenida en un sistema" (...), ya que se trata de áreas inútiles para el hombre, y que gracias a ello, "asumen los caracteres de una nueva naturaleza entrópica" (...).

Esta ponencia tiene como objetivo principal exponer los fundamentos conceptuales y formales del proyecto pictórico personal Paisajes enantrópicos -iniciado en el año 2016 y todavía en proceso ${ }^{6}$-, en el que se profundiza en las relaciones que el ser humano

\footnotetext{
${ }_{1}^{1}$ CARERI, F. Walkscapes. El andar como práctica estética. Barcelona: Editorial Gustavo Gili, 2002, p. 51.

${ }^{2}$ OLIVARES, R. (2011). El paraíso en la sala de estar. En: Revista Exit, 2011, n 41 , p. 8.

${ }^{3}$ AUGÉ, M. Los no lugares. Espacios del anonimato (una antropología de la sobremodernidad). Barcelona: Editorial Gedisa, 2004.

${ }^{4}$ RODRÍGUEZ SÁNCHEZ, C. J. (2015). Transigrafías. Caminar como práctica artístico-pedagógica. En: URBS. Revista de Estudios Urbanos y Ciencias Sociales, 2015, volumen 5, $n^{\circ} 1$, p. 40.

${ }^{5}$ ALCAIDE RAMÍREZ, A. Naturofagia: Un proyecto sobre el desencuentro con lo Otro. En: BARAÑO, K. y P. ESCANERO, P. (Eds.),

Support/Surface. El sentido de la piel: Soporte y develamiento. Ekfrasis \& Scuoiatura. Alicante: Fundación Cañada Blanch, 2015, p. 204.

${ }^{6}$ Continua ampliándose con nuevas piezas.
} 
establece con la naturaleza, según los términos descritos en los párrafos anteriores. ${ }^{7}$ En realidad, se trata de la segunda fase de un proyecto mayor integrado por tres series: la primera de ellas, titulada Naturofagia (2014-), se centra en la humanización del territorio llevada a sus límites más extremos, una deglución del hombre del medio natural de consecuencias devastadoras para éste (ver Ilustración 1); y la última, que se denominará Magnitud 9.5, valor numérico que en la escala de Richter se corresponde con sismos de efectos catastróficos y cifra más alta alcanzada por un terremoto desde que existen registros (Valdivia, Chile, 1960), ${ }^{8}$ focalizará su atención en la acción demoledora de los desastres naturales sobre los núcleos urbanos, convirtiendo su orden, pulcritud, seriación y estética controlada, en un caos producido por la versión más aguerrida de la naturaleza. En este caso, ésta no aprovecha el abandono del hombre para recuperar el espacio que le era propio, sino que ejerce sus derechos territoriales de forma violenta, borrando enérgicamente la huella de aquel. En ocasiones consigue anular totalmente su presencia, originando paisajes plenamente entrópicos, que son prueba de esa vuelta a su estado salvaje primigenio. Pero en otras -la mayoría de las veces- los restos del hombre siguen estando visibles, aunque en proporción variable en función de los casos; dando lugar a una segunda modalidad de "paisaje enantrópico".

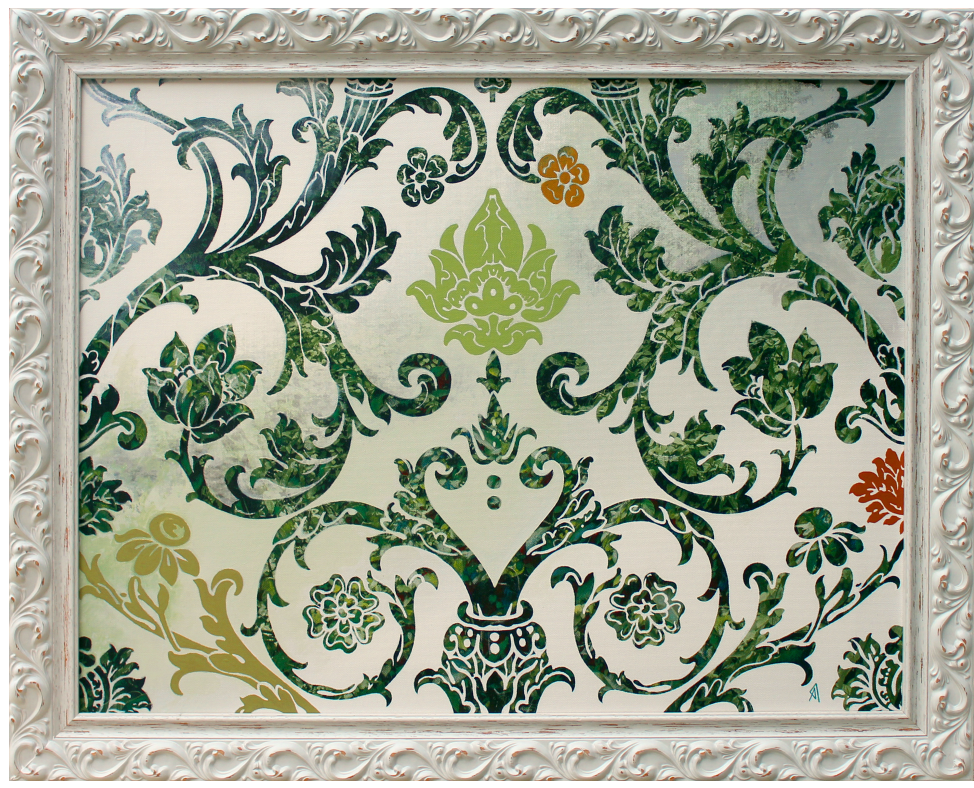

Ilustración 1. Classic Background I, 2014.

Técnica mixta sobre lienzo, $65 \times 50 \mathrm{~cm}$.

(Fotografía del fondo cortesía del artista Borja Morgado)

Paisajes enantrópicos: Un proyecto de pintura expandida sobre la humanización de la naturaleza en los espacios (peri)urbanos actuales.

Siguiendo la estela de los dadaístas, situacionistas, de Robert Smithson o del colectivo Stalker (este último más próximo en el tiempo), en el proyecto Paisajes enantrópicos reflexiono sobre las conexiones hombre-naturaleza en los territorios metropolitanos abandonados: lugares en los que la naturaleza se beneficia de la ausencia humana para reapropiarse del espacio que originalmente fue suyo, devolviéndole su aparente caos primigenio; entropía que el hombre anuló al imponer su dominio y control (antropización) y, en definitiva, al sustituir el paisaje natural por el artificial. Para ello y, al igual que los anteriores, utilizo la metodología del caminar como vehículo a través del cual acceder, descubrir y explorar estos espacios (peri)urbanos, ${ }^{9}$ para después registrarlos fotográficamente, analizarlos, aprehenderlos y representarlos utilizando diferentes dispositivos artísticos. Tanto esta serie como las tres que componen la trilogía están concebidas a modo de transigrafía, es decir, de "creación gráfica a partir de la interpretación y el conocimiento producido a partir del acto del caminar, planificadamente o no". ${ }^{10}$

\footnotetext{
${ }^{7}$ El proyecto ha sido expuesto en la muestra Naturaleza (peri)urbana, realizada en la Sala Mengolero de Rojales (Alicante) del 15 de julio al 21 de agosto de 2016 y en la titulada Desbordes, llevada a cabo en la Sala de Exposiciones CentroArte de Málaga, del 4 al 25 de marzo de 2017.

${ }^{8}$ ROMERO, S. ¿Cómo funciona la escala Richter? En: Muy interesante. Disponible en: http://www.muyinteresante.es/ciencia/preguntasrespuestas/como-funciona-la-escala-de-richter-501481801518 [consulta: 15 de marzo de 201].

${ }^{9}$ En concreto de las ciudades de Santa Fé (Granada) y San Vicente del Raspeig (Alicante).

${ }^{10}$ ALBALÁ y LÓPEZ, citados en rodríguez, Sánchez, C. J. Óp. Cit., p. 41.
} 
Paisajes enantrópicos. Un proyecto que reflexiona sobre las relaciones Hombre-Naturaleza en el espacio (peri)urbano abandonado III CONGRESO INTERNACIONAL DE INVESTIGACIÓN EN ARTES VISUALES :: ANIAV 2017 :: GLOCAL [codificar, mediar, transformar, vivir] http://dx.doi.org/10.4995/ANIAV.2017.4885

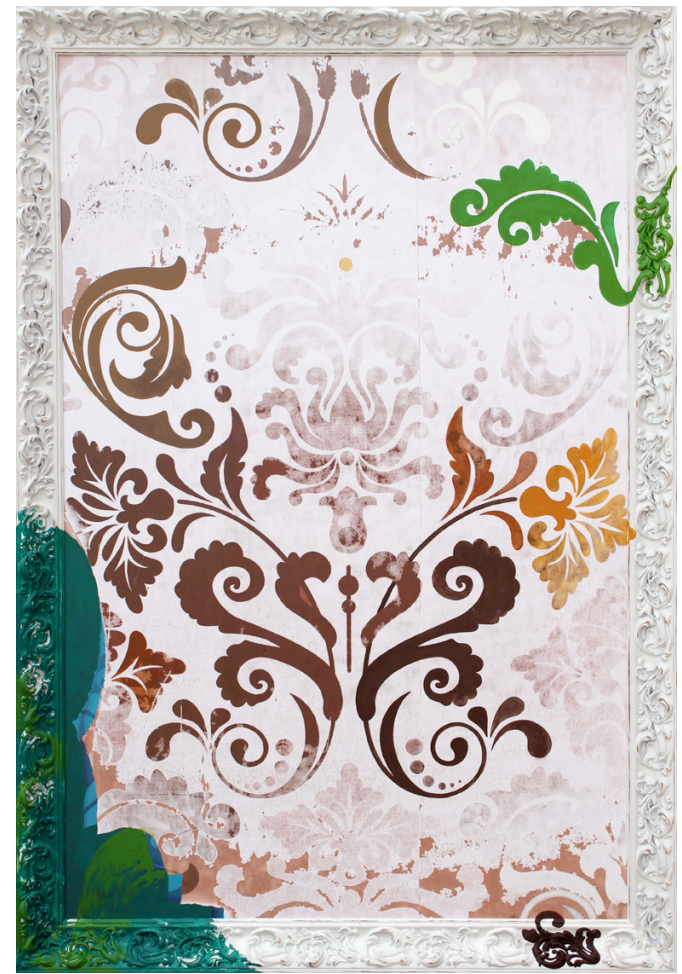

Ilustración 2. Paisaje enantrópico l, 2016.

Acrílico y lápices de colores sobre lienzo, $144 \times 90 \mathrm{~cm}$.

En las piezas que integran el proyecto la materia pictórica abstracta del fondo (metáfora de la naturaleza en su estado más salvaje, primitivo y entrópico) rasga y abre brechas en el papel de empapelar del primer plano (símbolo del ordenamiento, control y manipulación que ejerce el ser humano sobre el medio natural), a través de las cuáles "desborda" sus límites y restricciones, avanzando con libertad hacia el espectador. Este proceso se produce de forma gradual a lo largo de las obras que forman parte de la serie, pasando de composiciones dominadas por patrones vegetales artificiales y repetitivos (de base fotográfica y, por tanto figurativos, aunque dotados de un bajo grado de iconicidad) (ver ilustraciones 2, 3 y 4), a otras en las que las pinceladas gestuales y las manchas orgánicas adquieren el protagonismo compositivo (ver ilustraciones 5 y 6 ).

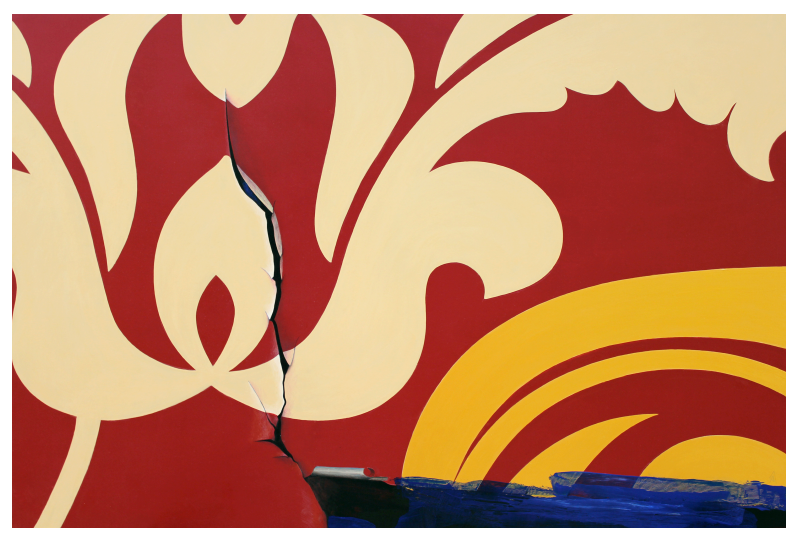

llustración 3. Paisaje enantrópico II, 2016.

Acrílico y lápices de colores sobre madera, $86.67 \times 130 \mathrm{~cm}$. 
Las obras que forman parte del proyecto son, por tanto, un claro ejemplo de experimentación en el campo de la pintura expandida, en donde el híbrido pintura-fotografía está muy presente, así como la investigación con diferentes soportes (papel, tela, madera, cartón e incluso los propios marcos de las obras), materiales (acrílico, lápices de colores, rotuladores o impresión digital entre otros) y lenguajes, ofreciendo un amplio espectro de matices desde el hiperrealismo más ortodoxo a la abstracción expresionista.

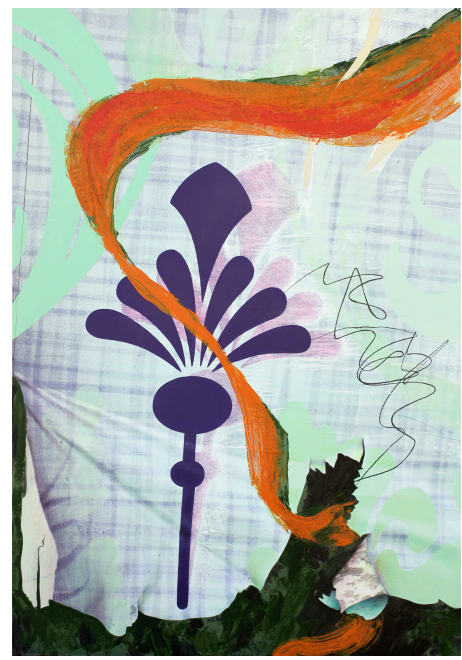

Ilustración 4. Paisaje enantrópico V, 2016.

Acrílico, lápices de colores e impresión digital sobre papel adherido a madera, 122x87 cm.

Finalmente, cabe subrayar que las dualidades plásticas, estilísticas y técnicas presentes en las obras del proyecto: pintura/fotografía, abstracción/figuración, fondo/figura, Ileno/vacío, orden/caos, mancha/gesto; frío/cálido, homogéneo/heterogéneo, unidad/multiplicidad etc., remiten en última instancia a los encuentros y desencuentros que entre hombre-naturaleza se producen en las ciudades actuales y sus alrededores, abogando por una relación más simbiótica entre ambos. En este sentido, las propuestas se sitúan conceptualmente próximas a las teorías ecosóficas -que no ecológicas- de Chatall Maillard, quien promueve un mayor acercamiento y, por tanto, sentimiento de la naturaleza, sustituir el "dominar y proteger" por el "volver a sentir, oír, a oler incluso, a comprender oliendo, a saber sintiendo. En vez de la pancarta 'no tocar' en los espacios protegidos, la invitación a la hierba, la educación del sentir, la religiosa invitación a saberse hierba y a pisarla como se pisa un templo en Oriente: con los pies descalzos" ${ }^{11}$

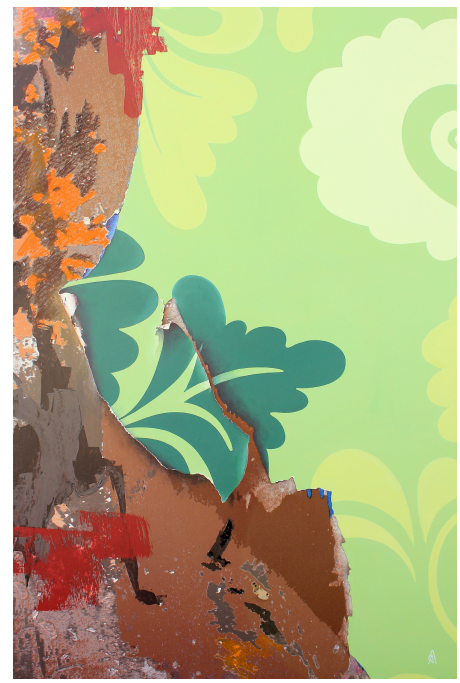

llustración 5. Paisaje enantrópico IV, 2016.

Acrílico, lápices de colores e impresión digital sobre cartón microcanal, 140x93.33 cm.

\footnotetext{
${ }^{11}$ MAILLARD, Ch. (Ed). El árbol de la vida. La naturaleza en el arte y las tradiciones de la India. Barcelona: Kairós, 2001, p. 13.
} 
Paisajes enantrópicos. Un proyecto que reflexiona sobre las relaciones Hombre-Naturaleza en el espacio (peri)urbano abandonado III CONGRESO INTERNACIONAL DE INVESTIGACIÓN EN ARTES VISUALES :: ANIAV 2017 :: GLOCAL [codificar, mediar, transformar, vivir] http://dx.doi.org/10.4995/ANIAV.2017.4885

\section{Conclusiones}

En los últimos años numerosos artistas se han interesado por el paisaje, especialmente por el cultural, es decir, por el originado como "resultado del desarrollo de actividades humanas en un territorio concreto". ${ }^{12}$ Al tratarse "de una realidad compleja, integrada por componentes naturales y culturales, tangibles e intangibles", ${ }^{13}$ deviene imposible acotarlo tipológicamente sin caer en el reduccionismo, de ahí que desde la práctica artística sean múltiples sus interpretaciones y representaciones. Dentro de este contexto debe ser entendido el proyecto pictórico Paisajes enantrópicos, como una posibilidad más entre las numerosas propuestas que desde el ámbito de la creación artística reflexionan sobre el binomio hombre-naturaleza en las metrópolis actuales. ¿Qué ocurre cuando el hombre deja de intervenir sobre un determinado espacio? ¿Cicatriza en algún momento la herida infringida en el paisaje? Y si es así, ¿de que manera la naturaleza sobrevive al impacto humano? A estas y otras preguntas pretende dar respuesta el proyecto Paisajes enantrópicos valiéndose para ello de un lenguaje alegórico, inmerso en los híbridos pintura-fotografía y abstracción-figuración.

Al mismo tiempo, este proyecto debe ser interpretado como una incitación al espectador a traspasar los límites, tanto los físicos como los mentales, los propios y los ajenos, para así conseguir que el "desencuentro" con lo Otro (la naturaleza), se transforme en un afortunado "encuentro".

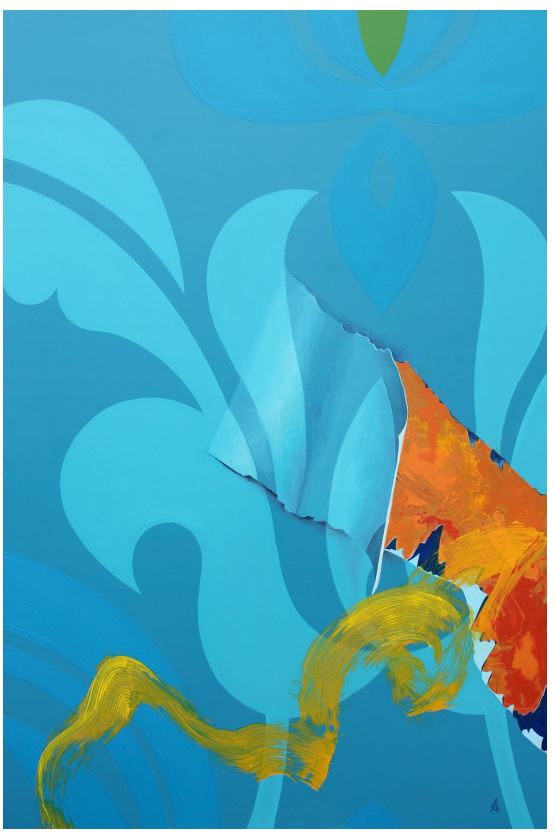

Ilustración 6. Paisaje enantrópico III, 2016.

Acrílico y lápices de colores sobre madera, $130 \times 86.67 \mathrm{~cm}$.

\footnotetext{
${ }^{12}$ OBSERVATORIO DE LA SOSTENIBILIDAD EN ESPAÑA (OSE). Patrimonio natural, cultural y paisajístico. Claves para la sostenibilidad territorial. Madrid: Ministerio de Medio Ambiente y Medio Rural y Marino, Fundación biodiversidad, Fundación Universidad de Alcalá, 2013, p. 27.
}

${ }^{13}$ ID. 


\section{FUENTES REFERENCIALES.}

ALCAIDE RAMÍREZ, A. Naturofagia: Un proyecto sobre el desencuentro con lo Otro. En: BARAÑO, K. y P. ESCANERO, P. (Eds.), Support/Surface. El sentido de la piel: Soporte y develamiento. Ekfrasis \& Scuoiatura. Alicante: Fundación Cañada Blanch, 2015, pp. 203-244.

AUGÉ, M. Los no lugares. Espacios del anonimato (una antropología de la sobremodernidad). Barcelona: Editorial Gedisa, 2004.

CARERI, F. Walkscapes. El andar como práctica estética. Barcelona: Editorial Gustavo Gili, 2002.

MAILLARD, Ch. (Ed). El árbol de la vida. La naturaleza en el arte y las tradiciones de la India. Barcelona: Kairós, 2001.

OBSERVATORIO DE LA SOSTENIBILIDAD EN ESPAÑA (OSE). Patrimonio natural, cultural y paisajístico. Claves para la sostenibilidad territorial. Madrid: Ministerio de Medio Ambiente y Medio Rural y Marino, Fundación biodiversidad, Fundación Universidad de Alcalá, 2013.

OLIVARES, R. (2011). El paraíso en la sala de estar. En: Revista Exit, 2011, no 41, pp. 8-9.

RODRÍGUEZ SÁNCHEZ, C. J. (2015). Transigrafías. Caminar como práctica artístico-pedagógica. En: URBS. Revista de Estudios Urbanos y Ciencias Sociales, 2015, volumen 5, no 1, pp. 35-56. Disponible en:

http://www2.ual.es/urbs/index.php/urbs/article/view/rodriguez_sanchez [consulta: 5 de marzo de 2017].

ROMERO, S. ¿Cómo funciona la escala Richter? En: Muy interesante. Disponible en: http://www.muyinteresante.es/ciencia/preguntasrespuestas/como-funciona-la-escala-de-richter-501481801518 [consulta: 15 de marzo de 201]. 